\title{
AS ENGRENAGENS DO PODER: SOBRE ALGUNS ENCAIXES ENTRE DIREITO, CIÊNCIAS E TRANSEXUALIDADES NO BRASIL
}

\section{Resumo}

No presente texto, busco demonstrar como nas questões jurídicas das pessoas trans os discursos jurídicos e científicos, especialmente derivados das ciências médicas e psi se articulam. Para tanto, analiso alguns julgamentos de tribunais de justiça brasileiros, ocorridos no período de 1970 a 2018. Argumento que existe uma pluralidade interna a cada um desses discursos e que diversas combinações são possíveis para produzir distintos efeitos práticos nas vidas das pessoas trans. Demonstro que na prática jurídica há uma seleção mais ou menos estratégica de quais discursos são acionados nas decisões, a depender dos efeitos desejados a serem produzidos.

Palavras-chave: Transexualidades, direito, ciência.

\begin{abstract}
The gears of power: On some adjustment between law, sciences and transgender lives in Brazil

The present work aims to demonstrate how the legal, medical and psy (psychiatry, psychology and psychiatry) discourses articulate in the legal debate on transgender rights. To this end, I analyze selected judgments from Brazilian courts, occurred in the 1970-2018 period. I claim that there is an internal plurality in each of those discourses and various combinations can be used to produce different practical effects in the lives of transgender people. I show that in the practice of law there is a strategic selection and combination of discourses, depending on the desired effect.
\end{abstract}

Keywords: Transgender, law, science.

\section{Resumen \\ Los engranajes del poder: sobre algunos ajustes entre Derecho, Ciencias y Transe- xualidades en Brasil \\ En el presente texto, busco demostrar cómo en las cuestiones jurídicas de las per- sonas trans los discursos jurídicos, médicos y psi se articulan. Por lo tanto, analizo algunos juzgados de tribunales brasileños, ocurridos en el período de 1970 a 2018. Argumento que existe una pluralidad interna a cada uno de esos discursos y que diversas combinaciones son posibles para producir distintos efectos prácticos en las vidas de las personas trans.}

Faculdade de Filosofia e Ciências Humanas da Universidade Federal de Minas Gerais, Belo Horizonte - MG | CEP 31270-901, Brasil.

Endereço postal: Av. Pres. Antônio Carlos, 6627 - Pampulha, Belo Horizonte - MG, 31270-901 Brasil.

Endereço eletrónico: thiagocoacci@gmail.com 
Demuestro que en la práctica jurídica a depender de los efectos deseados habrá una selección más o menos estratégica de qué discursos son accionados en las decisiones.

Palabras claves: Transexualidades, derecho, ciencia.

\section{Introdução}

O direito e as ciências são duas engrenagens pelas quais o poder opera, ambas atravessam, na contemporaneidade, toda nossa vida, restringindo e ao mesmo tempo criando novos modos de vida, novas regulações, novas normalizações, novos pontos de fuga. Essas engrenagens, no entanto, não funcionam como um bloco único, existem conflitos internos e múltiplos encaixes possíveis. Assim como Sheila Jasanoff (2004), acredito que as formas como conhecemos e representamos o mundo (social e natural) estão intimamente ligadas às formas como habitamos nele, ao produzir conhecimento estamos produzindo formas de habitar o mundo, por isso é tão importante observar e analisar criticamente os conhecimentos produzidos e os usos que lhes são dados.

No presente trabalho, busco demonstrar como nas questões jurídicas das pessoas trans ${ }^{1}$ os discursos jurídicos e científicos, especialmente aqueles das ciências médicas e psi (psicologia, psiquiatria e psicanálise), se articulam. Argumentarei que não existe um sentido correto segundo o qual cada uma dessas engrenagens gira e que os efeitos produzidos vão depender dos diversos encaixes possíveis dessas peças. Ou seja, o que me interessa observar é a forma como empiricamente os/as profissionais do direito vão fazer usos estratégicos de discursos científicos para negar ou conceder determinados pedidos jurídicos e quais os efeitos possíveis que isso pode ter. Para tanto, analiso alguns julgamentos de tribunais de justiça brasileiros, ocorridos no período de 1970 a 2018. A escolha dos casos não foi aleatória e buscou representar a pluralidade dos encaixes através do tempo e do território brasileiro. Além disso, busquei incluir na análise tanto casos paradigmáticos quanto casos corriqueiros. Dessa maneira, é possível perceber que esses encaixes ocorrem em todos os níveis de justiça e de maneira independente da relevância do caso.

De certa maneira, muitos trabalhos (Ventura 2010; Coacci 2013a; Teixeira 2013; Lima 2015; Lopes 2015; Freire 2016), mesmo que tangencialmente, já abordam os encaixes dessas engrenagens, no entanto, o enfoque aqui se diferencia por tentar ver os múltiplos encaixes na chave de uma dualidade risco/potência. Acredito que é justamente essa possibilidade de múltiplos encaixes que produz um risco de normalização, mas também cria a potência de aberturas mais democráti-

Opto aqui por utilizar o termo pessoas trans como um termo guarda-chuva que abarque homens e mulheres transexuais, travestis, transgêneros e outras identidades trans possíveis. Utilizarei outros termos de forma êmica, isto é, quando dialogando com um texto que utiliza outro termo ou ao referir a alguma pessoa que se identifica de forma diversa. 
cas, o que se concretizará depende do encaixe específico - e sempre provisório entre as engrenagens jurídicas e científicas em cada situação.

Ao longo do texto, o direito é tratado de forma distinta das outras ciências, e existem duas razões para isso. A primeira razão é de natureza metodológica, a forma como a análise é realizada parte do campo jurídico para o dos outros saberes: os textos e discursos fontes de minha análise são nativos a esse campo, os outros saberes emergem, no meu campo de pesquisa, à medida que são convocados para compor o campo jurídico. A segunda razão é de natureza prática, como será demonstrado adiante, existem conexões entre os campos jurídico e científico, e esses se retroalimentam, mas não é possível considerá-los como idênticos ou a mesma coisa. Cada campo possui uma série de mecanismos internos e regras próprias, bem como funções razoavelmente distintas na sociedade. A ciência jurídica, isto é, o campo de saber do direito, é um ser híbrido que habita a fronteira de ambos os campos.

\section{Da eterna incompletude do direito}

De uma forma geral, as pessoas têm a ideia de que ao se chegar para uma advogada com uma determinada demanda, ela abrirá um desses livros enormes que possuem inúmeras leis e encontrará ali, em alguma lei, a resposta para o problema. Para um determinado senso comum sobre o direito, na multidão de leis brasileiras se encontraria tudo o que é permitido e proibido e esse senso comum é, de alguma maneira, suportado pelo facto facto de que o Brasil adota o sistema de civil law, em que há uma centralidade da lei escrita para o direito.

Essa noção opera com, pelo menos, dois erros. Primeiro, o de que tudo está previsto nas leis. Apesar do número grande de leis existentes e em vigor no país, há uma série de questões que não estão previstas, ao menos de forma explícita, em nenhuma lei escrita. Segundo erro, o de que o direito brasileiro - mesmo sob o sistema de civil law - se reduziria à lei. Essa é uma noção reducionista, que é compartilhada não apenas pelo senso comum, mas inclusive por alguns/algumas juristas, até mesmo juízes(as) e desembargadores(as). No entanto, a Lei de Introdução às Normas do Direito Brasileiro, ${ }^{2}$ em seu artigo $4 .^{\circ}$, prevê como fontes do direito os princípios jurídicos, a analogia e os costumes. Isto é, a própria lei prevê que algumas respostas jurídicas possam derivar de outros lugares que não seja de uma lei escrita, nos casos em que a lei é omissa.

Além disso, nos primeiros contatos com o direito, nos livros de Introdução ao Estudo do Direito (ou da Ciência Jurídica, como querem alguns), é comum encontrar uma divisão entre disciplinas jurídicas e disciplinas auxiliares/afins ou ainda entre Dogmática e Zetética. Do lado jurídico (dogmático), geralmente são coloca-

$2 \quad$ Decreto-Lei 4657/1942. 
das disciplinas como Direito Civil, Direito Penal, Direito Constitucional, enquanto no lado «auxiliar» (Zetética) surgem disciplinas como Sociologia, Filosofia, Psicologia, Medicina Legal dentre outras. Esse rol pode variar a depender do autor ou do currículo da faculdade, e a forma como essas disciplinas são incorporadas ao direito também é muito variada (Jasanoff 1995; Ferraz Junior 2003; Reale 2012). Essa divisão é um tanto ou quanto curiosa e demonstra uma compreensão muito disciplinar dos saberes, mas o que me interessa aqui é apenas apontar para o facto de que o estudo das leis (e até mesmo do direito) não é suficiente para o jurista.

O direito contemporâneo é um fenômeno político e linguístico complexo e peculiar. Os enunciados jurídicos têm um poder de se fazer cumprir (o que de facto nem sempre ocorre), e o Estado possui mecanismos para garantir esse cumprimento, mesmo que para isso seja necessário o uso da força. No entanto, os significados desses signos linguísticos com os quais trabalhamos e que regulam a vida de cada um de nós não estão dados. Além disso, o direito não dá conta de saber sobre todas as realidades que regula. Sendo assim, precisamos convocar outros saberes para auxiliar no uso mais adequado do direito, para preencher de significado aquele conteúdo abstrato das regras jurídicas.

Não existem regras muito explícitas que orientem o funcionamento desse «preenchimento», podendo ser importados os saberes das disciplinas consideradas auxiliares ou ainda de outras que sejam consideradas relevantes para o caso em discussão, como a biologia, a sociologia ou derivados de potencialmente qualquer outro campo do saber. $\mathrm{O}$ uso desses saberes é quase sempre estratégico e, como mostra Jasanoff (1995), muitas vezes não preza pelo rigor científico próprio ao campo acionado. É o embate entre os diferentes atores na prática jurídica que controlará as fronteiras do campo jurídico, regulando o que pode ser ou não importado.

É justamente por esse caráter aberto do direito que é importante atentarmos para a forma como se dá, na prática jurídica, a convocação de outros saberes, nos perguntando sempre: quais saberes são convocados e como estes são acionados na prática jurídica? Especificamente para o caso em análise, isso significa tentar entender como os discursos jurídicos acionam os discursos médicos e psi e para que finalidades. Podemos, então, prosseguir para a análise desses encaixes.

\section{Um passado contemporâneo}

Antes de entrar na análise propriamente dita dos encaixes entre direito, ciências e transexualidades, tenho que fazer um pequeno adendo. Analisarei aqui demandas jurídicas de pessoas trans, mas na realidade essa categoria é bastante diversa. Algumas pessoas desejarão se hormonizar, outras não; algumas desejarão se submeter a cirurgias, outras não; algumas querem retificar seu nome e sexo nos documentos, outras não. Essas demandas não são universais para toda as pessoas 
trans, mas são aquelas que encontrei nos julgamentos que analisei e nos livros e artigos jurídicos que tratam sobre o tema. Além disso, é importante mencionar que as pesquisas de Coacci $(2013 b, 86)$ e Lima $(2015,1)$ não encontraram um único caso de retificação de nome e/ou gênero em que as demandantes fossem identificadas como travestis ou outras identidades no processo. Isso não quer dizer que a demanda de retificação de nome e/ou gênero é exclusiva de pessoas transexuais, mas diz da lógica como o discurso jurídico homogeneiza essa coletividade de pessoas. Pessoas identificadas como travestis aparecem mais comumente em processos criminais, como pode ser visto na pesquisa de Simone Becker e Hisadora Lemes (2015).

O direito brasileiro tem se baseado na concepção da patologia para reconhecer as demandas das pessoas trans (Coacci 2013b; Ventura 2010), tanto o acesso à saúde, quanto o direito à mudança de nome e sexo nos registros foram acessados por essa via até 2018. Em relação aos direitos das pessoas trans, Berenice Bento (2008) divide os países em dois grupos: aqueles que se orientam pela lógica do reconhecimento e aqueles da autorização. No primeiro grupo, se encontram países como a Argentina, Espanha e Malta que possuem legislações específicas que reconhecem as demandas jurídicas de pessoas trans, criando canais no próprio Estado para que elas sejam diretamente solucionadas. Atualmente, a Lei de Identidade de Gênero da Argentina ${ }^{3}$ e a de Malta ${ }^{4}$ são consideradas as que melhor atendem as demandas das pessoas trans, garantindo uma proteção ampla, e o tratamento digno em todas as esferas do Estado e da sociedade em função do gênero com o qual a pessoa se reconhece. Ambas as leis permitem, também, a alteração do prenome e do sexo das pessoas trans maiores de 18 anos, bastando a requisição. Não há, nesses países, a necessidade de a pessoa ter realizado qualquer cirurgia, intervenção corporal ou possuir diagnóstico médico de qualquer patologia para que esse direito seja concedido. Recentemente, o Brasil ingressou nesse rol de países por meio da decisão do Supremo Tribunal Federal (STF) na Ação Direta de Inconstitucionalidade (ADI) 4275.

O segundo grupo abarca países em que a história é completamente diferente. Por não possuírem legislações específicas, submetem cada demanda individual ao poder judiciário, ficando à mercê dos/das magistrados/as o reconhecimento ou não dos direitos reivindicados. Há no Brasil alguns projetos de lei que reconhecem alguns direitos de pessoas trans, sendo o mais importante o PL 5002/2013, chamado de Lei João W. Nery ou Lei de Identidade de Gênero (Brasil - Câmara dos Deputados 2013), de autoria de Jean Wyllys (PSOL/RJ) e Erika Kokay (PT/DF). Esse projeto é muito similar ao já existente na Argentina, basicamente uma adaptação daquele para o nosso direito.

$3 \quad$ Ley 26.743 de 2012.

Act. N. ${ }^{\circ}$ XI de 2015. 
Enquanto não houve a aprovação de legislação específica ou de uma decisão judicial com caráter vinculante, alguns direitos foram e ainda são garantidos às pessoas trans por meio de portarias de órgãos da administração direta e indireta brasileira, como é o caso do direito ao uso do nome social nos atendimentos do sistema único de saúde. Essas portarias muitas vezes são insuficientes ou ainda são frágeis, tendo sua eficácia limitada por desconhecimento dos funcionários do serviço público ou inclusive por preconceito. Um claro exemplo da fragilidade das portarias é o caso da PRT SAS/MS 859 de 30 de julho de 2013, do Ministério da Saúde. Tal portaria reduziria a idade necessária para o início do processo transexualizador de 18 para 16 anos, mas foi revogada em menos de 24 horas pela PRT GM/MS N. ${ }^{\circ} 1.579$, de 31 de julho de 2013.

Se é verdade que o Legislativo Federal permanece silente em relação aos direitos das pessoas trans, esse não é um tema novo para os estudos jurídicos, nem para o Judiciário. Hoje surpreende, mas pouco tempo atrás o direito discutia se as cirurgias de transgenitalização configurariam um crime. Um dos primeiros médicos a realizar as cirurgias no Brasil, o dr. Roberto Farina, após apresentar um trabalho no XV Congresso Brasileiro de Urologia (em 1975), no qual descrevia a técnica de algumas cirurgias que tinha realizado, recebeu uma ingrata surpresa: uma denúncia do Ministério Público por lesão corporal, na qual foi condenado em primeira instância e posteriormente absolvido no recurso (Tribunal de Alçada de São Paulo 1979).

Nesse momento, a justiça e a doutrina do direito discutiam: será que as cirurgias de transgenitalização são legais? Começam, então, lá na década de 1970, as articulações entre os discursos jurídicos, médicos e psi que vão influenciar até hoje nas questões sobre direitos das pessoas trans no Brasil. Para responder sobre a legalidade ou não dessa cirurgia realizada por Farina, o direito acionou os saberes médicos e psi, mas não quaisquer deles. Dentre as estratégias utilizadas pela defesa, optou-se por trazer ao processo dois pareceres de especialistas: um de Hilário Veiga de Carvalho, professor de medicina legal da Faculdade de Medicina da Universidade de São Paulo, e outro do criminalista Heleno Fragoso.

Foram propostas perguntas distintas para cada especialista, focando em seu campo de atuação. Para o prof. Hilário de Carvalho, o parecer requisitado era focado na literatura médica, assim, três foram as perguntas que se desejava ver respondidas: «1..$\left.^{\circ}\right)$ Pode-se considerar cientificamente definida uma síndrome denominada de 'transexualismo'? 2. ${ }^{\circ}$ ) Em caso positivo, qual a conduta médica a adotar? $3^{\circ}$ ) No evento constante dos autos, foi a conduta médica ética e cientificamente correta?» (Carvalho 1981, 289). Para Fragoso, focou-se no Direito Penal e a consulta buscava que respondesse «se realmente o acusado praticou o crime que a ele foi atribuído» (Fragoso 1981, 299).

Apesar das diferenças nos pareceres, ambos operam um encaixe similar entre as engrenagens dos discursos jurídicos e médicos. A estratégia discursiva do Professor Hilário de Carvalho faz com que a ciência médica seja a responsável por 
traçar os limites da lei (Carvalho 1981, 294). É mais interessante observar a forma como Fragoso opera, uma vez que a esse foi questionado especificamente sobre a questão jurídica. Vejamos.

5. Não será possível decidir com exatidão o caso submetido a julgamento, sem que se tenha clara idéia do que constitui o transexualismo. Trata-se de uma questão nova, de que não tratam os livros de medicina legal ao estudar a sexologia forense.

$[\ldots]$

7. Trata-se de anomalia hoje bem caracterizada e conhecida, claramente distinta de outros fenômenos de intersexualidade, como o homossexualismo e o transvestismo. Entende-se por transexualismo uma inversão da identidade psico-social, que conduz a uma neurose reacional obsessivo-compulsiva, que se manifesta pelo desejo de reversão sexual integral. A etiologia do transexualismo (que é fenômeno relativamente raro) é basicamente desconhecida, embora existam várias hipóteses especulativas. [...] O desconhecimento das causas levou à formulação de definições fenomenológicas, com as quais se descreve o fenômeno. Assim, o professor JOHN MONEY, uma das maiores autoridades na matéria, entende que o transexualismo constitui um distúrbio na identidade do próprio gênero, no qual a pessoa manifesta, com persistente e constante convicção, o desejo de viver como membro do sexo oposto integralmente. (Fragoso 1981, 299)

A estratégia de Fragoso é clara: afirmar que o direito não pode agir no caso sem levar em conta a produção científica sobre a transexualidade, daí importa para o caso toda uma literatura médico-psiquiátrica que apontava a pessoa transexual como doente. A decisão dependeria menos do conteúdo específico do art. 129 do Código Penal e mais do conteúdo científico. Nas passagens seguintes, Fragoso argumentou que os estudos demonstravam que terapias de conversão não seriam eficientes para curar a pessoa transexual, sendo, então, a cirurgia indicada como a terapêutica para o caso. Apesar dessas considerações extremamente patologizantes, Fragoso, na seção seguinte de seu parecer, dá uma ênfase grande ao consentimento da pessoa que levaria à exclusão da ilicitude e poderia, nesse caminho, apontar para uma outra forma das engrenagens girarem e se encaixarem, mas termina retornando à patologia para afirmar que o médico não possuía dolo, agia com a intenção de curar e não de lesar.

$\mathrm{O}$ acórdão que inocentou Roberto Farina seguiu muito dos pareceres. $\mathrm{O}$ texto trouxe o histórico dos diversos diagnósticos que uma das pacientes de Farina foi submetida para comprovar a existência da doença do transexualismo, ${ }^{5}$ e argumentou, ainda, que a paciente não obteve melhoras por via de tratamentos psicoterápicos e psiquiátricos, restando, então, a cirurgia como uma única alternativa terapêutica (Tribunal de Alçada de São Paulo 1979, 357). gêneros criada pelos discursos médicos e psi. 
O Tribunal confirmou a posição apontada por Fragoso: foi o facto de o Dr. Roberto Farina agir com uma finalidade terapêutica, para curar uma suposta doença, que permitiu que o caso fosse decidido absolvendo o médico. A psicologia e a psiquiatria foram utilizadas para diagnosticar uma doença, o transexualismo, mas se mostraram incapazes de solucionar o problema - isto é, converter a pessoa de volta ao suposto normal - com seu arcabouço terapêutico, passando, dessa maneira, a competência para outra área da medicina, a cirurgia plástica, que ao menos ajudaria a aliviar o sofrimento da pessoa. Por esse encaixe de saberes, a engrenagem do direito não deveria girar no sentido da proibição da cirurgia e o encaixe foi feito.

É interessante perceber que esse caso, de grande repercussão midiática na época, produziu o PL 1909/1979 que modificava o código penal, inserindo um parágrafo no art. 129 em que afirmava que as cirurgias de ablação de órgãos e partes do corpo não seriam crimes em caso de necessidade médica e com a autorização do paciente. A justificativa do projeto trazia explicitamente menção ao caso Farina (Brasil - Câmara dos Deputados 1979).

Estranhamente, esse projeto de lei chegou a ser aprovado, mas no dia 4 de junho de 1984 foi vetado pelo presidente Figueiredo. A justificativa do veto também acionou o discurso da medicina. Se a certeza da medicina foi o que inocentou Farina, aqui já aparece um outro encaixe dessas engrenagens, é a incerteza da ciência que é acionada para legitimar o veto. Segundo o presidente:

observa o Ministério da Saúde que os trabalhos científicos sobre o transexualismo, quando não tendenciosos, são polêmicos e limitam-se a registrar casos isolados sem tecer quaisquer considerações de caráter teórico. A literatura própria menciona complicações pós-operatórias, morbidade, mortalidade e perturbações psíquicas dos pacientes. As estatísticas são omissas quanto aos percentuais de êxito do tratamento [...]. Fundado nessas razões, resolvi vetar, integralmente, por contrário ao interesse público, o projeto em causa. (Figueiredo 1984, 1-2 [40-41])

O debate relatado até agora ocorreu nas décadas de 1970 e 1980 . Desde então muita coisa mudou e, em 1997, o Conselho Federal de Medicina (CFM) emitiu a Resolução 1482/1997, em que autorizou a realização das cirurgias de transgenitalização em caráter experimental. Mesmo com essa resolução, que pacificou o debate sobre a cirurgia ser ou não crime, encontrei em um julgamento do TJMG, de 2004, um desembargador que teceu comentários sobre a legalidade de se realizarem tais procedimentos. O desembargador defendia a tese de que o CFM teria competência apenas para regular no âmbito da ética médica, mas que no âmbito jurídico tal cirurgia ainda seria criminalizada e dependeria de autorização judicial caso a caso (Tribunal de Justiça de Minas Gerais 2004).

É interessante notar que tal afirmação da transexualidade como crime foi realizada em recurso civil e não criminal; não encontrei julgamento criminal algum em razão da cirurgia após a década de 1980. O questionamento da legalidade da 
cirurgia bem como da validade jurídica das normas que regulamentam a cirurgia pelo SUS ${ }^{6}$ é uma questão clara de conflito entre as engrenagens do direito e da ciência sobre quem é competente para regular o caso. Como já afirmado antes, a produção de conhecimento influencia as nossas formas de vida - e é curioso notar que o desembargador do caso afirme que faz esse debate apenas «a título meramente acadêmico» (Tribunal de Justiça de Minas Gerais 2004) - e esse conflito, em última instância, é sobre a distribuição seletiva de acesso à saúde e à cidadania. Dizer que essas normas não possuem validade jurídica é afirmar quem tem o direito de acessar um sistema de saúde que se pretende universal, é negar a cidadania a certos sujeitos e dizer que sua forma de vida não é legitimada pelo Estado. $\mathrm{O}$ esforço meramente acadêmico do desembargador, se seguido por outros, pode ter efeitos muito concretos na vida de diversas pessoas.

Essa retomada histórica, mesmo que pouco sistemática, é importante. Muita da forma como o discurso jurídico sobre as pessoas trans aciona o discurso médico e psi, e ainda quais discursos médicos e psi são acionados, está presente até hoje e teve sua origem ali. Como já demonstrado por outras pesquisas empíricas (Coacci 2013a; Lima 2015) que analisaram de forma mais sistemática as decisões sobre demandas das pessoas trans, grande parte dos votos, desfavoráveis e até mesmo os favoráveis, recorrem à classificação da transexualidade como uma patologia e recorrem ao CID-10 para justificar suas decisões.

Diversas decisões contemporâneas argumentam, de forma similar ao acórdão da década de 1970, que, na ausência de um tratamento psiquiátrico ou farmacológico eficiente para adequar o psíquico ao biológico, a cirurgia seria necessária para apaziguar o sofrimento desses sujeitos, configurando-se numa espécie de cura. Além disso, não há uma padronização na forma como os/as desembargadores(as) se referem à transexualidade como uma doença: síndrome do transexualismo, distúrbio de identidade de gênero, disforia de gênero, anomalia, neurodiscordância de gênero, desvio psicológico de identidade sexual. Todos esses termos são usados indistintamente, ocorrendo o uso de mais de uma terminologia no mesmo voto. Todavia, as terminologias têm diferentes origens e significados, não podendo ser tomadas como sinônimos indistintamente (Barbosa 2015). Isso demonstra que esses/essas desembargadores(as) não estão propriamente preocupados com a correção no uso dessa literatura, e esse é um uso estratégico, uma espécie de pedágio pago para a concessão ou negação dos direitos das pessoas trans.

Quando alguém deseja negar o direito, o discurso médico e psi sobre o sexo é acionado para apontar a fixidez do sexo e a mentira gerada pela cirurgia de transgenitalização. Vejamos:

Atualmente em vigor trata-se da Portaria GM/MS N. ${ }^{\circ} 2.803$, de 19 de novembro de 2013, e da Resolução CFM N. ${ }^{\circ}$ 1.652/02. No caso das decisões anteriores a esse período, pode referir-se a Portaria n. ${ }^{\circ} 1.707$, de 18 de agosto de 2008, e a já referida Resolução CFM n. ${ }^{\circ}$ 1.482/97, dentre outras. 
Outrossim, levando em consideração que o registro de nascimento deve conter a realidade, não considero possível a retificação do sexo no registro civil. Isso porque, apesar da intervenção cirúrgica e da alteração de nome, o autor ainda é, geneticamente, do sexo masculino, o que pôde ser constatado através do exame acostado às f. 60, onde se constatou a presença de cromossomos XY, pertinentes exclusivamente ao sexo masculino (Tribunal de Justiça de Minas Gerais 2006).

De outra maneira, quando alguém deseja conceder o direito à mudança do nome ou do gênero, a patologia surge para demonstrar uma certa naturalidade do fenômeno e a ausência de vontade/liberdade do sujeito sobre o gênero (Tribunal de Justiça de Minas Gerais 2010). A mudança não seria, então, uma decisão e desejo do sujeito, mas uma necessidade decorrente da patologia.

A verdade construída no processo é baseada em grande medida nos saberes médicos e psi. É frequente que os votos apresentem longa teorização acerca da transexualidade, com grande presença de literatura médica específica sobre a transexualidade, inclusive literatura internacional, como é o caso dos textos de Harry Benjamin, Robert Stoller e John Money, autores que já estavam mencionados no acórdão do caso Farina. Estranha a ausência de literatura das ciências sociais, que tanto têm produzido sobre o assunto, estranha também a ausência do discurso da própria pessoa. A autonomia da pessoa sobre seu próprio corpo e identidade não parece existir se não mediado pelo discurso dos outros.

A forma como as engrenagens dos discursos jurídicos e científicos se encaixaram nas últimas décadas, fez com que, para o ingresso da ação de retificação de nome e gênero de pessoas trans, fosse frequentemente exigido: i) um diagnóstico de transexualismo, preferencialmente emitido por equipe multidisciplinar conforme prevista nas portarias do processo transexualizador; ii) que a pessoa esteja passando pelo processo transexualizador, se hormonizando e realizando intervenções corporais para deixar seu gênero mais supostamente real; iii) que a cirurgia de transgenitalização já tenha sido realizada, no caso de mulheres transexuais (Coacci 2013a; Lentz 2013; Freire 2016). Podiam pedir ainda a realização de perícia especializada durante o processo, a juntada de outros documentos, como fotos do dia a dia e a indicação de testemunhas, tudo para demonstrar, contra uma paranoica suspeita, que a pessoa é transexual de verdade e não havia má-fé por trás do desejo de mudar de nome e gênero. Por não existir regulamentação explícita sobre o tema, cada juiz apresentava exigências diferentes, abrindo mão de algum dos itens acima ou acrescentando outros, o que de facto já aconteceu com frequência.

\section{Um futuro em construção}

Nos últimos anos, é possível observar uma mudança gradual. A resistência micropolítica que as pessoas trans fazem em seu cotidiano ao acessar os serviços 
de saúde e de atendimento jurídico, a pressão dos movimentos sociais LGBT e Trans e a enorme produção acadêmica têm gerado algumas mudanças nos discursos científicos e jurídicos sobre as pessoas trans (Coacci 2018). A despatologização da transexualidade tornou-se o elefante na sala, é preciso discuti-la seja para suportar essa causa ou ainda discordar estrategicamente, como é feito por algumas ativistas que temem a perda de direitos pela despatologização. Exemplo disso, é a publicação da Resolução 01/2018 pelo Conselho Federal de Psicologia, que proíbe as terapias de conversão de pessoas transexuais. Devido a essas pressões e aos novos discursos, tem sido possível ver reflexos no atual processo de revisão da CID, que, ao que tudo indica, deve retirar as experiências trans do rol de patologias mentais ainda em 2018.

Essas mudanças nos discursos médicos e psi têm sido incorporadas pelo discurso jurídico. Mais recentemente, houve uma mudança radical nesse cenário jurídico brasileiro, a partir da decisão da Ação Direta de Inconstitucionalidade 4275 pelo $\mathrm{STF}^{7}$. Tal ação originalmente discutia apenas a possibilidade de retificação de nome e gênero sem a necessidade de cirurgia de transgenitalização. Assim, o voto do ministro relator, Marco Aurélio Mello, primeiro a analisar e votar sobre o caso, inicialmente reconheceu a desnecessidade dessas cirurgias. $\mathrm{O}$ que permitiu essa forma de decisão foi um encaixe das engrenagens que separa sexo e gênero numa forma de oposição entre corpo e mente; mas diferentemente daqueles que negam o direito, Marco Aurélio dá uma preponderância para o gênero como fonte de direito, principalmente por esse expor as pessoas trans ao sofrimento. Além disso, o ministro defendeu que, na ausência da cirurgia, ainda era preciso comprovar a transexualidade de outras maneiras e se remeteu aos critérios utilizados pelo Conselho Federal de Medicina, na Portaria 1955/2010, que atualmente regulamenta as cirurgias de transgenitalização (Mello 2018). Isso por si só já é uma mudança em relação ao estado das coisas e um novo encaixe das engrenagens, mas o julgamento não se encerrou aí.

O voto do ministro Edson Fachin (2018) alterou ainda mais a situação. Além das cirurgias, o ministro divergiu do Relator e dispensou qualquer tipo de alteração física, laudo e parecer médico ou psicológico que comprovem a transexualidade, até mesmo as ações judiciais foram dispensadas. O procedimento, nos termos do voto do ministro, deveria ser realizado diretamente em cartório e ter como condicionante apenas a declaração da vontade da pessoa de retificar. É importante perceber a diferença de estratégia argumentativa entre Fachin e Marco Aurélio. Diferentemente da maioria dos juristas analisados até aqui, Fachin não conceitua a transexualidade, seu caminho argumentativo é outro e passa pela defi-

\footnotetext{
A íntegra do acórdão não se encontrava publicada até o fechamento do texto. Todavia, os votos do relator e do ministro Edson Fachin se encontravam publicados pelo próprio STF, o que permitiu a análise aqui. É possível que venham a sofrer pequenas alterações na versão final para o acórdão, todavia a análise se mantém, por ter sido essa a versão lida no plenário no dia do julgamento.
} 
nição de identidade de gênero. Tal termo surge nos estudos sobre intersexualidade e transexualidade, mas da forma como utilizado, a partir do conceito previsto nos Princípios de Yogyakarta e replicado na OC 14/2017 da Corte Interamericana de Direitos Humanos (CIDH), permite outra entrada para o debate, sem passar pela literatura médica patologizante. Essa estratégia argumentativa não coloca um valor a priori para as experiências trans, como o caminho que inicia pagando o pedágio da natureza da transexualidade. Identidade de gênero, da forma como manejada, é um conceito amplo e que coloca em par de igualdade múltiplas formas de identificação que podem ou não corresponder com o sexo atribuído no nascimento. Essa compreensão permite que as engrenagens girem de outra maneira e tanto na referida OC 14/2017 quanto no voto de Fachin se conectem a identidade de gênero aos princípios jurídicos de liberdade e da dignidade da pessoa humana. $\mathrm{O}$ ministro cita longa passagem da opinião consultiva nesse sentido da Corte Interamericana:

Sobre esse ponto, deve-se recordar que a identidade de gênero foi definida nesta opinião como a vivência interna e individual do gênero tal como cada pessoa o sente, o qual pode ou não corresponder com o sexo assinalado no momento do nascimento. (...) o reconhecimento da identidade de gênero encontra-se ligada necessariamente à ideia segundo a qual o sexo e o gênero devem ser percebidos como parte de uma construção identitária que resulta da decisão livre e autônoma de cada pessoa, sem que se deve estar sujeita à sua genitália. (CIDH apud Fachin 2018, 12)

É essa conexão que vai abrir as portas para se compreender as exigências de processo judicial, cirurgia de transgenitalização, laudo ou qualquer prova da real transexualidade da pessoa como uma forma de discriminação que deve ser vedada. $\mathrm{O}$ voto do ministro Edson Fachin foi seguido pela maioria dos outros ministros, se tornando vencedor. A decisão do STF nesse julgamento tem efeito vinculante e garante em todo o Brasil o direito à retificação de nome e gênero administrativamente, sem a necessidade de cirurgia, laudos ou qualquer outro tipo de comprovação da transexualidade. Essa decisão marca uma importante virada nas formas de conexão entre as diversas engrenagens jurídicas e científicas.

\section{Conclusões}

Demonstrei que há uma pluralidade interna tanto ao discurso jurídico quanto aos discursos científicos, bem como diversos encaixes possíveis. A compreensão das experiências trans como patológicas serviu para negar e conceder direitos, $\mathrm{O}$ preço desses encaixes foi um reforço mútuo entre direito e discursos patológicos, que selecionava apenas um rol limitado de formas consideradas legítimas a serem trans para obter o reconhecimento jurídico. Ficando excluídas, assim, as pessoas 
que por qualquer razão não podiam ou não desejavam se submeter às condições muito específicas que eram exigidas por esses encaixes. Mais recentemente, as engrenagens giraram e parecem consolidar um encaixe que dispensa os saberes patológicos para a concessão de direitos, apontando para um reconhecimento da autonomia dos sujeitos para decidirem sobre si. Essa é uma forma mais democrática, por incluir uma gama mais ampla de sujeitos que buscam o reconhecimento de seu gênero, sem obrigar que se submetam a um processo que, muitas vezes, reatualiza normas de gênero muito rígidas e provoca sofrimento.

Se, no momento, foi possível observar a consolidação temporária de um encaixe mais democrático, isso já pode estar ameaçado. Muitos dos saberes que sustentaram esse novo encaixe estão sob ataque em uma cruzada contra a famigerada «ideologia de gênero» (Miskolci e Camapana 2017). Nada impede que outros encaixes venham a ocorrer no futuro que incorporem esses novos saberes aversos aos direitos sexuais e não há como saber de antemão quais serão esses encaixes futuros, nem quais seus possíveis efeitos. É a partir dos encaixes que se define, afinal, em que medida o risco de normalização e a potência de abertura democrática se concretizarão. A busca por um direito mais democrático implica necessariamente em uma reflexão profunda não apenas sobre se concederemos ou não um direito, mas também sobre quais enquadramentos e articulações discursivas utilizaremos para fazer essa concessão, pois isso terá efeitos práticos nas vidas das pessoas.

\section{Referências bibliográficas}

Barbosa, Bruno Cesar. 2015. Imaginando Trans: saberes e ativismos em torno das regulações das transformações corporais do sexo. Tese de Doutorado. São Paulo: Universidade de São Paulo. Faculdade de Filosofia, Letras e Ciências Humanas.

Becker, Simone, e Hisadora Beatriz G. Lemes. 2015. «Vidas vivas inviáveis: Etnografia sobre os homicídios de travestis no Tribunal de Justiça de Mato Grosso do Sul». Revista Ártemis 18 (1). Disponível em http://periodicos.ufpb.br/index.php/artemis/article/ view $/ 22545$

Bento, Berenice. 2008. O que é Transexualidade? São Paulo: Brasiliense.

Brasil - Câmara dos Deputados. 1979. «Projeto de Lei 1909 de 1979». Disponível em http:// www.camara.gov.br/proposicoesWeb/prop_mostrarintegra?codteor $=1180106 \&$ filename=Dossie $+-\mathrm{PL}+1909 / 1979$

—. 2013. «Lei João W. Nery». Disponível em http://www.camara.gov.br/proposicoesWeb/fichadetramitacao?idProposicao $=565315$

Carvalho, Hilário V. de. 1981. «Transexualismo. Diagnóstico - Conduta médica a ser adotada». Revista dos Tribunais 545 (março): 289-298.

Coacci, Thiago. 2013a. «'Eu tenho um amo implacável: a natureza das coisas’: discursos jurídicos acerca das transexualidades no Tribunal de Justiça de Minas Gerais (19892010)». Diálogo 24 (dezembro): 45-62.

- 2013b. «A transexualidade no/pelo judiciário mineiro: um estudo dos julgados do TJMG correlatos à transexualidade no período 2008 a 2010». Revista Três [...] Pontos 2: 81-92. 
2018. Conhecimento Precário e Conhecimento Contra-público: a coprodução dos conhecimentos e dos movimentos sociais de pessoas trans no Brasil. Tese de Doutorado. Belo Horizonte: Universidade Federal de Minas Gerais. Faculdade de Filosofia e Ciências Humanas.

Fachin, Edson. 2018. «Voto-vogal. Ação Direta de Inconstitucionalidade 4275». Brasília: Supremo Tribunal Federal. Disponível em http://www.stf.jus.br/arquivo/cms/noticiaNoticiaStf/anexo/ADI4.275VotoEF.pdf

Ferraz Júnior, e Tércio Sampaio. 2003. Introdução ao estudo do direito: técnica, decisão, dominação. São Paulo: Ed. Atlas.

Figueiredo, João. 1984. «Mensagem 171», 4 de junho de 1984. http://www.camara.gov.br/ proposicoesWeb/prop_mostrarintegra?codteor $=1180106 \&$ filename $=$ Dossie + PL + 1909/1979

Fragoso, Heleno. 1981. «Transexualismo. Conceito - Distinção do homossexualismo». Revista dos Tribunais 545: 298-304.

Freire, Lucas. 2016. «Sujeitos de Papel: Sobre a Materialização de Pessoas Transexuais e a Regulação do Acesso a Direitos». Cadernos Pagu 48. DOI: https://doi.org/10.1590/18094 449201600480013

Jasanoff, Sheila. 1995. Science at the bar: law, science, and technology in America. Cambridge, MA: Harvard University Press.

-. 2004. «Ordering Knowledge, Ordering Society». In States of knowledge: the co-production of science and social order, organizado por Sheila Jasanoff, 13-45. London; New York: Routledge.

Lentz, Luisa Helena Stern. 2013. «Direito à identidade: viva seu nome. A retificação do registro civil como meio de conquista da cidadania para travestis e transexuais». In Seminário Internacional Fazendo Gênero 10 (Anais Eletrônicos). Florianópolis: UFSC.

Lima, Luiza Ferreira. 2015. «A ‘verdade' produzida nos autos: uma análise de decisões judiciais sobre retificação de registro civil de pessoas transexuais em Tribunais brasileiros». Dissertação de Mestrado. São Paulo: Universidade de São Paulo. Faculdade de Filosofia, Letras e Ciências Humanas.

Lopes, Laís. 2015. "Corpos e práticas da pessoalidade: a emergência e a desconstrução da identidade de gênero». Dissertação de Mestrado. Belo Horizonte: Universidade Federal de Minas Gerais. Faculdade de Direito e Ciências do Estado.

Mello, Marco Aurélio. 2018. «Voto. Ação Direta de Inconstitucionalidade 4275». Brasília: Supremo Tribunal Federal. Disponível em http://www.stf.jus.br/arquivo/cms/noticiaNoticiaStf/anexo/ADI4.275VotoEF.pdf

Miskolci, Richard, e Maximiliano Campana. 2017. «'Ideologia de gênero': notas para a genealogia de um pânico moral contemporâneo». Sociedade e Estado 32 (3): 725-748. DOI: https://doi.org/10.1590/s0102-69922017.3203008

Reale, Miguel. 2012. Lições preliminares de direito. 27. ${ }^{a}$ ed., 11. ${ }^{a}$ tiragem. São Paulo: Saraiva.

Teixeira, Flavia do Bonsucesso. 2013. Dispositivos de dor: saberes - poderes que (con)formam as transexualidades. São Paulo: Annablume; Fapesp.

Tribunal de Alçada de São Paulo. 1979. «Apelação Criminal 201.999». Relator: Des. Denser de Sá. Apelado: Roberto Farina. Vítima: Waldirene Nogueira. São Paulo: Tribunal de Alçada de São Paulo.

Tribunal de Justiça de Minas Gerais. 2004. «Embargos Infringentes 1.0000.00.296076-3/ 001». Relator: Des. Carreira Machado. Belo Horizonte: Tribunal de Justiça de Minas Gerais. 
_ 2006. «Apelação Cível 1.0543.04.9105116-001». Relator: Des. Roney Oliveira. Belo Horizonte: Tribunal de Justiça de Minas Gerais.

. 2010. «Apelação Cível 1.0024.09.672096-6-001». Relator: Des. Alvim Soares. Belo Horizonte: Tribunal de Justiça de Minas Gerais.

Ventura, Miriam. 2010. A transexualidade no tribunal: saúde e cidadania. Rio de Janeiro: EdUERJ.

Thiago Coacci. Advogado, mestre e doutor em Ciência Política. Faculdade de Filosofia e Ciências Humanas da Universidade Federal de Minas Gerais (UFMG), Brasil. Endereço eletrónico: thiagocoacci@gmail.com

Artigo recebido a 3 de maio de 2018 e aceite para publicação a 3 de agosto de 2018. 
